\title{
Synthesis, Crystal Structures, Characterization and Catalytic Property of Manganese(II) Complexes Derived from Hydrazone Ligands
}

\author{
Yao Tan \\ School of Environmental and Chemical Engineering, Chongqing Three Gorges University, Chongqing 404000, P.R. China \\ *Corresponding author: E-mail: 18696838310@163.com
}

Received: 05-23-2020

\begin{abstract}
A new bromido-coordinated mononuclear manganese(II) complex $\left[\mathrm{MnL}^{1} \mathrm{Br}_{2}\left(\mathrm{OH}_{2}\right)\right](\mathbf{1})$, and a new nitrato-coordinated mononuclear manganese(II) complex $\left[\mathrm{Mn}\left(\mathrm{L}^{2}\right)_{2}\left(\mathrm{ONO}_{2}\right)\left(\mathrm{OH}_{2}\right)\right] \mathrm{NO}_{3}$ (2), with the hydrazone ligands 4-hydroxy- $N^{\prime}$-(pyridin-2-ylmethylene)benzohydrazide ( $\left.\mathrm{HL}^{1}\right)$ and $N^{\prime}$-(pyridin-2-ylmethylene)isonicotinohydrazide $\left(\mathrm{HL}^{2}\right)$, have been synthesized and structurally characterized by physico-chemical methods and single crystal X-ray determination. Single crystal structural analysis shows that the $\mathrm{Mn}$ atom in complex $\mathbf{1}$ is in octahedral coordination, and that in complex $\mathbf{2}$ is in pentagonal bipyramidal coordination. The catalytic property for epoxidation of styrene by the complexes was evaluated.
\end{abstract}

Keywords: Manganese complex; hydrazone ligand; crystal structure; catalytic property

\section{Introduction}

Hydrazone compounds are a series of important ligands in coordination chemistry. ${ }^{1}$ The hydrazone ligands are capable of binding various transition and rare earth metal atoms to form complexes with versatile structures and properties. ${ }^{2}$ To date, most hydrazone complexes have been reported to have remarkable catalytic properties, such as asymmetric epoxidation, oxidation of sulfides, and various type of polymerization. ${ }^{3}$ Among the complexes, those with $\mathrm{Mn}$ centers are of particular interest for their catalytic properties. ${ }^{4}$ In this paper, a new bromido-coordinated mononuclear manganese(II) complex $\left[\mathrm{MnL}^{1} \mathrm{Br}_{2}\right.$ $\left.\left(\mathrm{OH}_{2}\right)\right](\mathbf{1})$, and a new nitrato-coordinated mononuclear manganese(II) complex $\left[\mathrm{Mn}\left(\mathrm{L}^{2}\right)_{2}\left(\mathrm{ONO}_{2}\right)\left(\mathrm{OH}_{2}\right)\right] \cdot \mathrm{NO}_{3}(2)$, with the hydrazone ligands 4-hydroxy- $N^{\prime}$-(pyridin-2-ylmethylene)benzohydrazide ( $\left.\mathrm{HL}^{1}\right)$ and $N^{\prime}$-(pyridin-2-ylmethylene)isonicotinohydrazide $\left(\mathrm{HL}^{2}\right)$ (Scheme 1$)$, are presented.<smiles>O=C(N/N=C/c1ccccn1)c1ccc(O)cc1</smiles>

$\mathrm{HL}^{1}$<smiles>O=C(N/N=C/c1ccccn1)c1ccncc1</smiles>

$\mathrm{HL}^{2}$
Scheme 1. The preparation of the hydrazone ligands $\mathrm{HL}^{1}$ and $\mathrm{HL}^{2}$.

\section{Experimental}

\section{1. Materials}

Manganese bromide, manganese nitrate, 2-pyridinecarboxaldehyde, 4-hydroxybenzohydrazide, and 4-pyridylcarbonylhydrazine were purchased from Aldrich. All other reagents with AR grade were used as received without further purification.

\section{2. Physical Measurements}

Infrared spectra $\left(4000-400 \mathrm{~cm}^{-1}\right)$ were recorded as $\mathrm{KBr}$ discs with a FTS-40 BioRad FT-IR spectrophotometer. Microanalyses $(\mathrm{C}, \mathrm{H}, \mathrm{N})$ of the complex were carried out on a Carlo-Erba 1106 elemental analyzer. Solution electrical conductivity was measured at $298 \mathrm{~K}$ using a DDS- 11 conductivity meter. GC analyses were performed on a Shimadzu GC-2010 gas chromatograph.

\section{3. X-Ray Crystallography}

Crystallographic data of the complexes were collected on a Bruker SMART 1000 CCD area diffractometer with graphite monochromated Mo-K $\alpha$ radiation $(\lambda=0.71073 \AA)$ at $298(2) \mathrm{K}$. Absorption corrections were applied by using the multi-scan program. ${ }^{5}$ The structures of the complexes were solved by direct methods and successive Fourier dif- 
ference syntheses, and anisotropic thermal parameters for all nonhydrogen atoms were refined by full-matrix leastsquares procedure against $F^{2} .5$ All non-hydrogen atoms were refined anisotropically. The water and amino $\mathrm{H}$ atoms were located from electronic density maps and refined isotropically with $\mathrm{O}-\mathrm{H}, \mathrm{N}-\mathrm{H}$ and $\mathrm{H} \cdot \cdots \mathrm{H}$ distances restrained to $0.85(1), 0.90(1)$ and $1.37(2) \AA$, respectively. The crystallographic data and experimental details for the structural analysis are summarized in Table 1.

Table 1. Crystallographic data for the single crystal of the complexes.

\begin{tabular}{lll}
\hline Compound & $\mathbf{1}$ & $\mathbf{2}$ \\
\hline Empirical formula & $\mathrm{C}_{13} \mathrm{H}_{13} \mathrm{Br}_{2} \mathrm{MnN}_{3} \mathrm{O}_{3}$ & $\mathrm{C}_{24} \mathrm{H}_{22} \mathrm{MnN}_{10} \mathrm{O}_{9}$ \\
Formula weight & 474.02 & 649.46 \\
Temperature (K) & $298(2)$ & $298(2)$ \\
Crystal system & Monoclinic & Triclinic \\
Space group & $P{ }_{1} / n$ & $P-1$ \\
$a(\AA)$ & $8.1584(7)$ & $9.1540(13)$ \\
$b(\AA)$ & $16.6952(14)$ & $10.3954(15)$ \\
$c(\AA)$ & $12.0488(10)$ & $14.4801(17)$ \\
$\alpha\left({ }^{\circ}\right)$ & 90 & $83.219(2)$ \\
$\beta\left(^{\circ}\right)$ & $96.255(2)$ & $86.581(2)$ \\
$\gamma\left({ }^{\circ}\right)$ & 90 & $89.383(2)$ \\
$V\left(\AA^{3}\right)$ & $1631.4(2)$ & $1365.8(3)$ \\
$Z$ & 4 & 2 \\
$F(000)$ & 924 & 666 \\
Data/restraints/ & $4008 / 4 / 209$ & $5088 / 5 / 409$ \\
parameters & 1.062 & 1.049 \\
Goodness-of-fit on $F^{2}$ & $0.0475,0.1375$ \\
$R_{1}, w R_{2}[I>2 \sigma(I)]$ & $0.0380,0.0977$ & $0.0747,0.1639$ \\
$R_{1}, w R_{2}$ (all data) & $0.0609,0.1070$ & \\
\hline
\end{tabular}

\section{4. Synthesis of $\left[\mathrm{MnL}^{1} \mathrm{Br}_{2}\left(\mathrm{OH}_{2}\right)\right]$ (1)}

2-Pyridinecarboxaldehyde $(1.0 \mathrm{mmol}, 0.11 \mathrm{~g})$ was reacted with 4-hydroxybenzohydrazide $(1.0 \mathrm{mmol}, 0.15 \mathrm{~g})$ in methanol $(20 \mathrm{~mL})$ for $30 \mathrm{~min}$ at room temperature with stirring. Then, manganese bromide tetrahydrate (1.0 mmol, $0.29 \mathrm{~g}$ ) was added, and the mixture was stirred at room temperature for another $30 \mathrm{~min}$. The deep brown solution was evaporated to remove three quarters of the solvents under reduced pressure, yielding brown solid product of the complex. Yield: $63 \%$. Well-shaped single crystals suitable for X-ray diffraction were obtained by recrystallization of the solid from methanol. Anal. calcd. for $\mathrm{C}_{13} \mathrm{H}_{13} \mathrm{Br}_{2} \mathrm{MnN}_{3} \mathrm{O}_{3}$ (\%): C, 32.94; $\mathrm{H}, 2.76 ; \mathrm{N}, 8.86$. Found (\%): C, 32.76; H, 2.83; N, 8.77. IR data $\left(\mathrm{KBr}, \mathrm{cm}^{-1}\right): 3465$, $1645,1446,1366,1161,1069,952,860,537$. UV-Vis data in methanol $\left[\lambda_{\max }(\mathrm{nm})\right]: 292,375$.

\subsection{Synthesis of \\ $\left[\mathrm{Mn}\left(\mathrm{L}^{2}\right)_{2}\left(\mathrm{ONO}_{2}\right)\left(\mathrm{OH}_{2}\right)\right] \mathrm{NO}_{3}(2)$}

2-Pyridinecarboxaldehyde ( $1.0 \mathrm{mmol}, 0.11 \mathrm{~g})$ was reacted with 4-pyridylcarbonylhydrazine $(1.0 \mathrm{mmol}, 0.14 \mathrm{~g})$ in methanol $(20 \mathrm{~mL})$ for $30 \mathrm{~min}$ at room temperature with stirring. Then, manganese nitrate tetrahydrate $(1.0 \mathrm{mmol}$, $0.25 \mathrm{~g}$ ) was added, and the mixture was stirred at room temperature for another $30 \mathrm{~min}$. The deep brown solution was evaporated to remove three quarters of the solvents under reduced pressure, yielding brown solid product of the complex. Yield: $36 \%$. Well-shaped single crystals suitable for X-ray diffraction were obtained by recrystallization of the solid from methanol. Anal. calcd. for $\mathrm{C}_{24} \mathrm{H}_{22} \mathrm{Mn}$ $\mathrm{N}_{10} \mathrm{O}_{9}$ (\%): C, 44.39; H, 3.41; N, 21.57. Found (\%): C, 44.53; $\mathrm{H}, 3.50 ; \mathrm{N}, 21.49$. IR data $\left(\mathrm{KBr}, \mathrm{cm}^{-1}\right): 3440,1645$, $1551,1468,1445,1433,1412,1384,1358,1312,1218,1153$, 1107, 1160, 1036, 1004, 920, 850, 782, 749, 690, 589, 520. UV-Vis data in methanol $\left[\lambda_{\max }(\mathrm{nm})\right]: 297,370$.

\section{6. Styrene Epoxidation}

The epoxidation reaction catalyzed by the complexes was carried out at room temperature in $\mathrm{MeCN}$ under nitrogen atmosphere. The reaction mixture contains styrene (2.00 mmol), chlorobenzene (internal standard; 2.00 $\mathrm{mmol}$ ), the complex (catalyst; $0.10 \mathrm{mmol}$ ) and iodosylbenzene or sodium hypochlorite (oxidant; $2.00 \mathrm{mmol}$ ), and $\mathrm{MeCN}(5.00 \mathrm{~mL})$. When sodium hypochlorite was used as the oxidant, the solution was buffered to $\mathrm{pH}=11.2$. GC was used to determine the composition of reaction medium with styrene and styrene epoxide quantified by the internal standard method (chlorobenzene). For each catalyst, the reaction time for the maximum epoxide yield was determined by withdrawing periodically $0.1 \mathrm{~mL}$ aliquots from the mixture and this time was used to monitor the efficiency of the catalyst on performing at least two independent experiments. Blank experiments with each oxidant and using the same experimental conditions without catalyst were carried out.

\section{Results and Discussion}

\section{1. Synthesis}

The hydrazones were facile prepared by reaction of 2-pyridinecarboxaldehyde with 4-hydroxybenzohydrazide and 4-pyridylcarbonylhydrazine, respectively, in $\mathrm{MeOH}$. The complexes $\mathbf{1}$ and $\mathbf{2}$ were synthesized from the hydrazones with manganese bromide tetrahydrate (for $\mathbf{1}$ ) and manganese nitrate tetrahydrate (for 2) in $\mathrm{MeOH}$ (Scheme 2). Notably, even though the synthetic procedures are different, the structure of the bromido-coordinated complex $\mathbf{1}$ is similar to the chlorido-coordinated manganese(II) complex. ${ }^{6}$ In the synthesis of the chlorido-coordinated manganese(II) complex, triethylamine was added to remove the hydrogen of the amino group. To the best of our knowledge, it is no need to introduce triethylamine in the preparation of Schiff base complexes. The molar conductivities $\left(\Lambda_{\mathrm{M}}=35 \Omega^{-1} \mathrm{~cm}^{2} \mathrm{~mol}^{-1}\right.$ for $\mathbf{1}$ and $138 \Omega^{-1} \mathrm{~cm}^{2} \mathrm{~mol}^{-1}$ for 2 ) are consistent with the values expected for non-electrolyte and 1:1 electrolyte. ${ }^{7}$ 


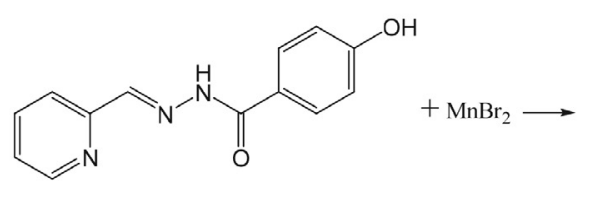

$\mathrm{HL}^{1}$<smiles></smiles>

$\mathrm{HL}^{2}$<smiles></smiles>

(1)

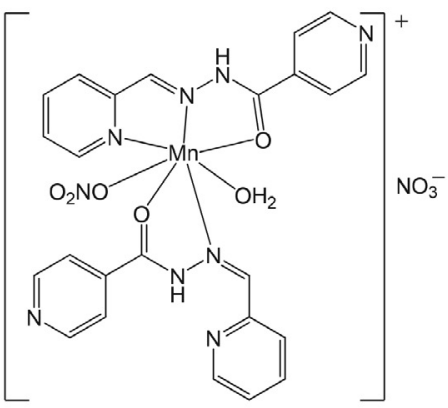

(2)

Scheme 2. The preparation of the complexes.

\section{2. Description of the Structure of Complex 1}

Single-crystal X-ray analysis reveals that compound $\mathbf{1}$ is a bromido-coordinated mononuclear manganese(II) complex. The ORTEP plot of the complex is shown in Figure 1 . The manganese atom is in a distorted octahedral geometry, which is coordinated by the $\mathrm{N}_{2} \mathrm{O}$ donor atoms of the hydrazone ligand and one $\mathrm{Br}$ atom in the equatorial plane, and one $\mathrm{Br}$ atom and one water $\mathrm{O}$ atom in the axial positions. The distortion of the octahedral coordination of the structure can be observed from the bond angles (Table 2 ) related to the $\mathrm{Mn}$ atom. The cis- and trans-angles related to the $\mathrm{Mn}$ atom are in the range of 69.48(9)-118.88(7) ${ }^{\circ}$ and $140.29(10)-173.42(7)^{\circ}$, respectively. The bond lengths of $\mathrm{Mn}-\mathrm{O}$ and $\mathrm{Mn}-\mathrm{N}$ (Table 2) are close to those in other Mn complexes with Schiff base ligands. ${ }^{8}$ As expected, the bond lengths in the axial positions are elongated due to a Jahn-Teller distortion effect. The hydrazone ligand coordinates to the $\mathrm{Mn}$ atom through neutral state. The molecules are linked through $\mathrm{N}-\mathrm{H} \cdots \mathrm{Br}, \mathrm{O}-\mathrm{H} \cdots \mathrm{Br}$ and $\mathrm{O}-\mathrm{H} \cdots \mathrm{O}$ hydrogen bonds (Table 3), to generate chains along the $c$ axis (Figure 2).

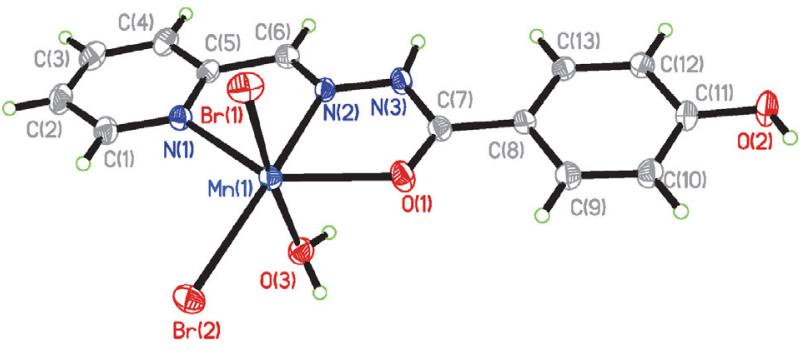

Figure 1. ORTEP diagram of complex 1 (30\% thermal ellipsoid).

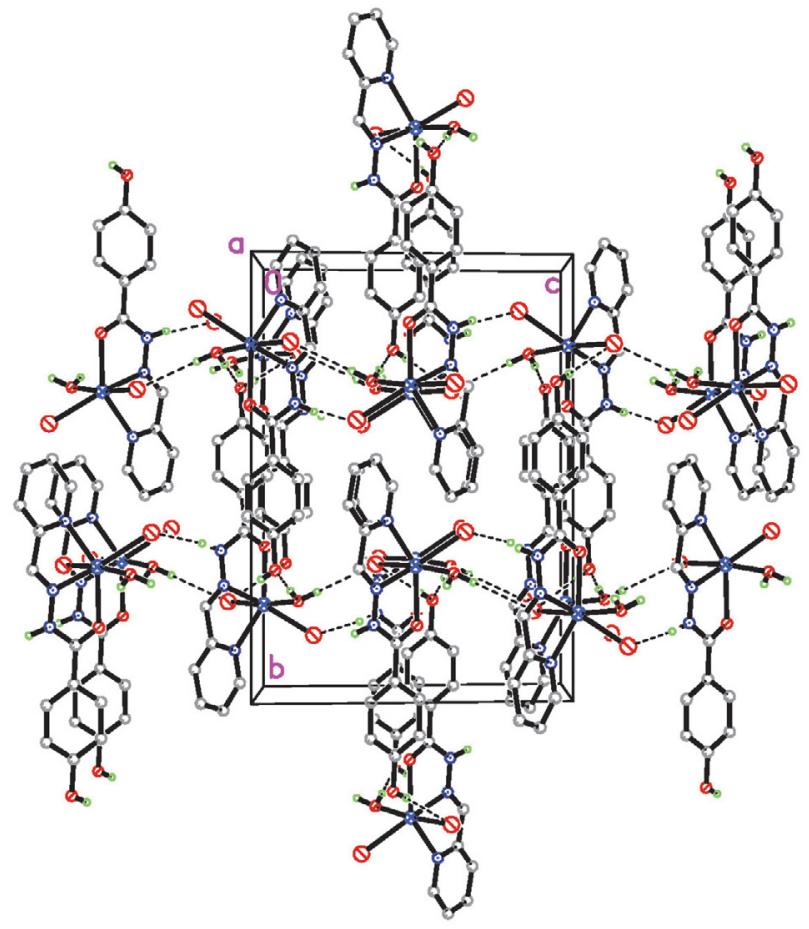

Figure 2. Molecular packing structure of complex 1 linked by hydrogen bonds.

\section{3. Description of the Structure of Complex 2}

Single-crystal X-ray analysis reveals that compound 2 is a nitrato-coordinated mononuclear manganese(II) complex. The compound contains a $\left[\mathrm{Mn}\left(\mathrm{L}^{2}\right)_{2}\left(\mathrm{ONO}_{2}\right)\right.$ $\left.\left(\mathrm{OH}_{2}\right)\right]$ cation and a nitrate anion. The ORTEP plot of the complex is shown in Figure 3. The manganese atom is in a 
distorted pentaganol-bipyramidal geometry, which is coordinated by the $\mathrm{N}_{2} \mathrm{O}$ donor atoms of one hydrazone ligand and the NO donor atoms of the other hydrazone ligand in the equatorial plane, and one nitrate $\mathrm{O}$ atom and one water $\mathrm{O}$ atom in the axial positions. The distortion of the pentagonal bipyramidal coordination of the structure can be observed from the bond angles (Table 2) related to the $\mathrm{Mn}$ atom. The equatorial angles related to the $\mathrm{Mn}$ atom are in the range of $65.99(8)-80.66(9)^{\circ}$ and 132.55(9)$149.33(9)^{\circ}$. The bond lengths of Mn-O and Mn-N (Table 2) are close to those in other Mn complexes with Schiff base ligands. ${ }^{7}$ The hydrazone ligands coordinate to the $\mathrm{Mn}$ atom through neutral state. The complex cations and the nitrate anions are linked through $\mathrm{N}-\mathrm{H} \cdots \mathrm{N}, \mathrm{O}-\mathrm{H} \cdots \mathrm{N}$, $\mathrm{O}-\mathrm{H} \cdots \mathrm{O}$ and $\mathrm{N}-\mathrm{H} \cdots \mathrm{O}$ hydrogen bonds (Table 3 ), to generate a network (Figure 4).

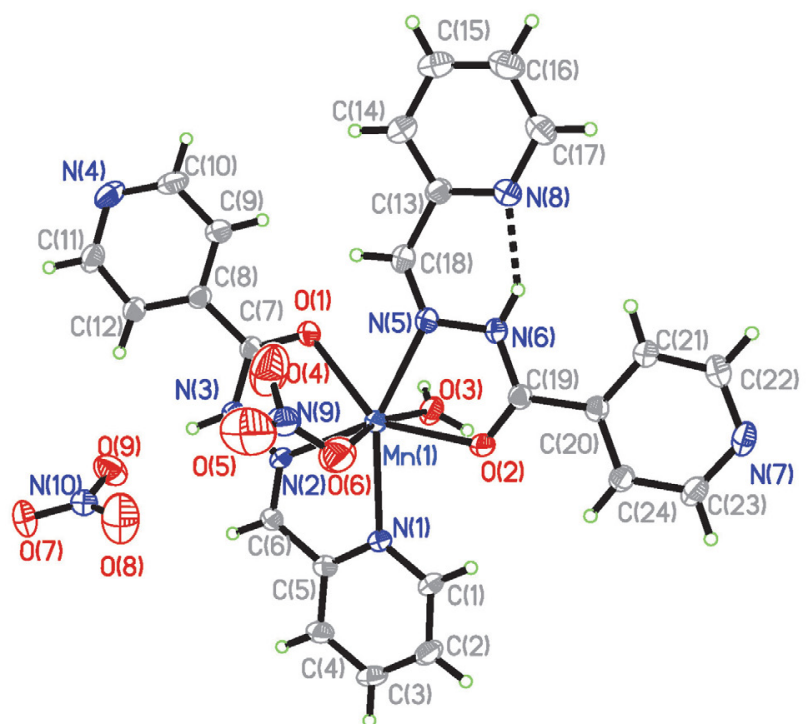

Figure 3. ORTEP diagram of complex 2 (30\% thermal ellipsoid).

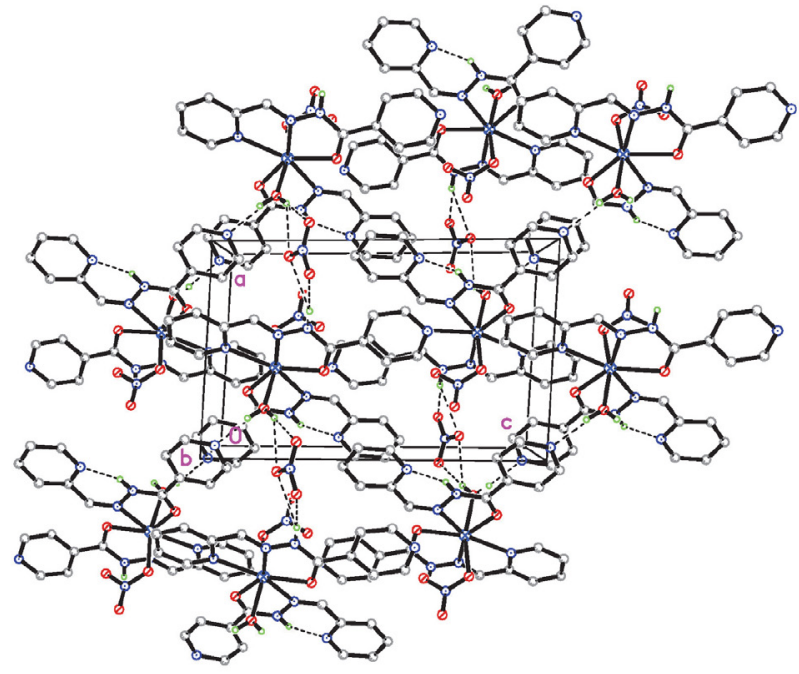

Figure 4. Molecular packing structure of complex 2 linked by hydrogen bonds.
Table 2. Selected bond distances $(\AA)$ and bond angles $\left(^{\circ}\right)$ for the complexes.

1

\begin{tabular}{lrll}
\hline Bond distance & & & \\
Mn1-N1 & $2.287(3)$ & Mn1-N2 & $2.229(3)$ \\
Mn1-O1 & $2.272(2)$ & Mn1-O3 & $2.265(3)$ \\
Mn1-Br2 & $2.5517(7)$ & Mn1-Br1 & $2.6499(7)$ \\
\hline Bond angle & & & \\
N2-Mn1-O3 & $82.62(10)$ & N2-Mn1-O1 & $69.48(9)$ \\
O3-Mn1-O1 & $83.37(10)$ & N2-Mn1-N1 & $70.81(10)$ \\
O3-Mn1-N1 & $91.24(10)$ & O1-Mn1-N1 & $140.29(10)$ \\
N2-Mn1-Br2 & $163.56(7)$ & O3-Mn1-Br2 & $84.37(7)$ \\
O1-Mn1-Br2 & $118.88(7)$ & N1-Mn1-Br2 & $99.53(7)$ \\
N2-Mn1-Br1 & $98.38(7)$ & O3-Mn1-Br1 & $173.42(7)$ \\
O1-Mn1-Br1 & $90.87(7)$ & N1-Mn1-Br1 & $95.24(7)$ \\
Br2-Mn1-Br1 & $95.69(2)$ & & \\
\hline
\end{tabular}

2

\begin{tabular}{llll}
\hline $\begin{array}{l}\text { Bond distance } \\
\text { Mn1-N1 }\end{array}$ & $2.387(3)$ & Mn1-N2 & $2.288(3)$ \\
Mn1-N5 & $2.363(3)$ & Mn1-O1 & $2.412(2)$ \\
Mn1-O2 & $2.263(2)$ & Mn1-O3 & $2.163(3)$ \\
Mn1-O6 & $2.226(3)$ & & \\
\hline Bond angle & & & \\
O3-Mn1-O6 & $164.30(11)$ & O3-Mn1-O2 & $83.24(9)$ \\
O6-Mn1-O2 & $83.05(11)$ & O3-Mn1-N2 & $94.49(10)$ \\
O6-Mn1-N2 & $93.40(12)$ & O3-Mn1-N5 & $91.89(11)$ \\
O6-Mn1-N5 & $90.26(12)$ & O3-Mn1-N1 & $87.25(10)$ \\
O6-Mn1-N1 & $83.02(11)$ & O3-Mn1-O1 & $83.05(9)$ \\
O6-Mn1-O1 & $112.58(11)$ & O2-Mn1-N2 & $149.33(9)$ \\
O2-Mn1-N5 & $68.81(8)$ & N2-Mn1-N5 & $141.84(9)$ \\
O2-Mn1-N1 & $80.66(9)$ & N2-Mn1-N1 & $68.67(9)$ \\
N5-Mn1-N1 & $149.33(9)$ & O2-Mn1-O1 & $143.07(8)$ \\
N2-Mn1-O1 & $65.99(8)$ & N5-Mn1-O1 & $77.56(9)$ \\
N1-Mn1-O1 & $132.55(9)$ & & \\
\hline
\end{tabular}

Table 3. Hydrogen bond distances $(\AA)$ and bond angles $\left({ }^{\circ}\right)$ for the complexes.

\begin{tabular}{|c|c|c|c|c|}
\hline$D-\mathrm{H} \cdots A$ & $d(D-H)$ & $d(\mathrm{H} \cdots A)$ & $d(D \cdots A)$ & $\begin{array}{l}\text { Angle } \\
(D-\mathrm{H} \cdots A)\end{array}$ \\
\hline \multicolumn{5}{|l|}{1} \\
\hline $\mathrm{N} 3-\mathrm{H} 3 \mathrm{~B} \cdots \mathrm{Br} 2$ & $0.90(1)$ & $2.445(14)$ & $3.329(3)$ & $169(5)$ \\
\hline $\mathrm{O} 3-\mathrm{H} 3 \mathrm{~A} \cdots \mathrm{Br} 1^{\# 1}$ & $0.85(1)$ & $2.518(14)$ & $3.354(3)$ & $169(4)$ \\
\hline $\mathrm{O} 3-\mathrm{H} 3 \mathrm{~B} \cdots \mathrm{O} 2^{\# 2}$ & $0.85(1)$ & $1.973(13)$ & $2.820(4)$ & 173(5) \\
\hline $\mathrm{O} 2-\mathrm{H} 2 \cdots \mathrm{Br} 1^{\# 3}$ & 0.82 & 2.46 & $3.268(3)$ & $167(5)$ \\
\hline \multicolumn{5}{|l|}{2} \\
\hline $\mathrm{O} 3-\mathrm{H} 3 \mathrm{~A} \cdots \mathrm{N} 7^{\# 4}$ & $0.84(1)$ & $1.971(14)$ & $2.801(4)$ & $169(5)$ \\
\hline $\mathrm{O} 3-\mathrm{H} 3 \mathrm{~B} \cdots \mathrm{O} 7^{\# 5}$ & $0.84(1)$ & $2.290(13)$ & $3.123(5)$ & $171(4)$ \\
\hline $\mathrm{O} 3-\mathrm{H} 3 \mathrm{~B} \cdots \mathrm{O} 8^{\# 6}$ & $0.84(1)$ & $2.33(3)$ & $2.934(5)$ & $129(3)$ \\
\hline 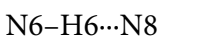 & $0.90(1)$ & $1.84(3)$ & $2.627(4)$ & $144(4)$ \\
\hline N3-H3 ‥O9 & $0.90(1)$ & $2.035(13)$ & $2.929(4)$ & $172(4)$ \\
\hline N3-H3 ‥O8 & $0.90(1)$ & $2.52(4)$ & $3.163(5)$ & $129(4)$ \\
\hline $\mathrm{N} 3-\mathrm{H} 3 \cdots \mathrm{N} 10$ & $0.90(1)$ & $2.63(2)$ & $3.480(4)$ & $157(4)$ \\
\hline
\end{tabular}

Symmetry codes: $\# 1:-1 / 2+x, 1 / 2-y,-1 / 2+z ; \# 2: 1-x, 1-y, 2-z$; \#3: $2-x, 1-y,-z ; \# 4: 2-x, 1-y, 2-z$; \#5: $1+x, y, z$. 


\section{4. Spectral Characterization}

The weak and broad absorptions in the region 3430$3470 \mathrm{~cm}^{-1}$ are attributed to the $\mathrm{O}-\mathrm{H}$ bonds of the phenol groups and water ligands. The intense bands at $1645 \mathrm{~cm}^{-1}$ are assigned to the vibration of the $\mathrm{C}=\mathrm{N}$ groups. ${ }^{9}$ Nitrato complexes show IR bands in the range 1410-1448 $\left(v_{5}\right)$, 1290-1317 $\left(v_{1}\right)$, and 1073-1077 $\mathrm{cm}^{-1}\left(v_{2}\right)$ due to NO stretches. ${ }^{10}$ The value of $\Delta\left(v_{5}-v_{1}\right)$, i.e., $102-131 \mathrm{~cm}^{-1}$, suggests monodentate coordination. The spectrum of complex 2 has $v_{5}$ at $1312 \mathrm{~cm}^{-1}$ and $v_{1}$ at $1433 \mathrm{~cm}^{-1}$, and has the $\Delta\left(v_{5}-v_{1}\right)$ value of $121 \mathrm{~cm}^{-1}$. IR spectrum of complex 2 also shows a band at $1384 \mathrm{~cm}^{-1}$ due to ionic nitrate. ${ }^{11}$

In the UV-Vis spectra of the complexes, the bands at $370-375 \mathrm{~nm}$ are attributed to the azomethine chromophore $\pi-\pi^{*}$ transition. The bands at higher energy (290$300 \mathrm{~nm}$ ) are associated with the benzene $\pi-\pi^{*}$ transition. ${ }^{12}$

\section{5. Catalytic Epoxidation Results}

Epoxidation of styrene was carried out at room temperature with complexes $\mathbf{1}$ and $\mathbf{2}$ as the catalysts and PhIO and $\mathrm{NaOCl}$ as oxidants. The brown color of the solutions containing the catalysts and the substrate was intensified after the addition of oxidant indicating the formation of oxo-metallic intermediates of the catalysts. After completion of the oxidation reaction, the solution regains its initial color. The percentage of conversion of styrene, selectivity for styrene oxide, yield of styrene oxide and reaction time to obtain maximum yield using both the oxidants are given in Table 4. The data reveals that the complexes as catalysts convert styrene most efficiently in the presence of both oxidants. Nevertheless, the catalysts are selective towards the formation of styrene epoxides despite of the formation of by-products which have been identified by GCMS as benzaldehyde, phenylacetaldehyde, styrene epoxides derivative, alcohols etc. From the data it is also clear that the complexes exhibit excellent efficiency for styrene epoxide yield. When the reactions are carried out with $\mathrm{PhIO}$ and $\mathrm{NaOCl}$, most of the oxidation was occurred in the first one hour. When the reaction time was prolonged to two hours for complex $\mathbf{1}$ and three hours for complex $\mathbf{2}$, the styrene conversions were about 89 and $77 \%$ for complex $\mathbf{1}$, and 78 and $70 \%$ for complex $\mathbf{2}$, respectively. It is evident that between $\mathrm{PhIO}$ and $\mathrm{NaOCl}$, the former acts as a better oxidant with respect to both styrene conversion and styrene epoxide selectivity. The epoxide yields for the complexes $\mathbf{1}$ and 2 using $\mathrm{PhIO}$ and $\mathrm{NaOCl}$ as oxidants are
77 and 65\%, and 73 and 57\%, respectively. It is also obvious that complex 1 has better catalytic property than complex 2. Nitrogeneous ligands are reported to lengthen and weaken the $\mathrm{M}-\mathrm{O}$ bond in the oxidized form of the catalyst by donating electron density into the $\mathrm{M}-\mathrm{O}$ antibonding orbital, which can account for the improved reactivity. ${ }^{13}$

Kochi et al. reported epoxide yields of $50-75 \%$ for the epoxidation of various types of olefins, including substituted styrenes, stilbenes, and cyclic and acyclic alkenes, within $15 \mathrm{~min}$ at room temperature in acetonitrile using $\mathrm{PhIO}$ as the oxidant and several Mn(III)-salen complexes as catalysts. ${ }^{14}$ Hosseini-Monfared et al. reported the cyclohexene epoxide yield ranging from $43-68 \%$ in presence of $\mathrm{PhIO}$ as oxidant. ${ }^{6}$ Lei and Yang reported the styrene oxide yields of 75 and $60 \%$, respectively, with the oxidant $\mathrm{PhIO}$ and $\mathrm{NaOCl} .{ }^{15}$ Thus, manganese complexes with Schiff base and hydrazone ligands are a kind of excellent catalysts for the oxidation reactions.

\section{Conclusion}

A new bromido-coordinated mononuclear manganese(II) complex and a new nitrato-coordinated mononuclear manganese(II) complex derived from hydrazone ligands were prepared and characterized. Single crystal $\mathrm{X}$-ray analysis indicates that the $\mathrm{Mn}$ atom in complex $\mathbf{1}$ is in octahedral coordination, and that in complex $\mathbf{2}$ is in pentagonal bipyramidal coordination. The complexes have effective catalytic property for the epoxidation of styrene.

\section{Supplementary Data}

Supplementary data are available from the Cambridge Crystallographic Data Center (CCDC 1857989 for 1 and 1857990 for 2), 12 Union Road, Cambridge CB2 1EZ, UK (fax: +44-1223-336-033; e-mail: deposit@ccdc. cam.ac.uk; or via www.ccdc.cam.ac.uk/conts/retrieving. $\mathrm{html}$ ) on request, quoting the deposition numbers: CCDC 1403969.

\section{Acknowledgements}

This project was supported by the Scientific and Technological Research Program of Chongqing Municipal Education Commission (Grant No. KJQN201801222), the Chunhui Project from Education Ministry of China (Grant No. Z2015140), and the Science and Technology Research

Table 4. Catalytic epoxidation results.

\begin{tabular}{llcccccc}
\hline Time (hour) & Oxidant & \multicolumn{2}{c}{ Conversion (\%) } & \multicolumn{2}{c}{ Epoxide yield (\%) } & \multicolumn{2}{c}{ Selectivity (\%) } \\
& & $\mathbf{1}$ & $\mathbf{2}$ & $\mathbf{1}$ & $\mathbf{2}$ & $\mathbf{1}$ & $\mathbf{2}$ \\
\hline 2 & $\mathrm{PhIO}$ & 89 & 78 & 77 & 73 & 92 & 83 \\
3 & $\mathrm{NaOCl}$ & 77 & 70 & 65 & 57 & 89 & 81 \\
\hline
\end{tabular}

Tan: Synthesis, Crystal Structures, Characterization ... 
Program of Chongqing Education Commission (No. KJQN202001243).

\section{References}

1. (a) S. Dasgupta, S. Karim, S. Banerjee, M. Saha, K. D. Saha, Dalton Trans. 2020, 49, 1232-1240; DOI:10.1039/C9DT04636D (b) N. Biswas, S. Bera, N. Sepay, T. K. Mukhopadhyay, K. Acharya, S. Ghosh, S. Acharyya, A. K. Biswas, M. G. B. Drew, New J. Chem. 2019, 43, 16714-16729; DOI:10.1039/C9NJ04171K (c) A. A. Khandar, Z. M. Azar, M. Eskandani, C. B. Hubschle, S. Van Smaalen, B. Shaabani, Y. Omidi, Polyhedron 2019, 171, 237-248; DOI:10.1016/j.poly.2019.06.026

(d) D. Kuriakose, M. R. P. Kurup, Polyhedron 2019, 170, 749761; DOI:10.1016/j.poly.2019.06.041

(e) M. Mehmood, Imtiaz-ud-Din, M. N. Tahir, B. Ihsan-Ul Haq, S. S. Zahra, Inorg. Chim. Acta 2019, 486, 387-394.

DOI:10.1016/j.ica.2018.10.009

2. (a) X.-W. Zhu, Acta Chim. Slov. 2018, 65, 939-945;

DOI:10.17344/acsi.2018.4607

(b) M. Liang, N. Sun, D.-H. Zou, Acta Chim. Slov. 2018, 65, 964-969; DOI:10.17344/acsi.2018.4625

(c) Z. You, H. Yu, Z. Li, W. Zhai, Y. Jiang, A. Li, S. Guo, K. Li, C. Lv, C. Zhang, Inorg. Chim. Acta 2018, 480, 120-126;

DOI:10.1016/j.ica.2018.05.020

(d) Z. You, H. Yu, B. Zheng, C. Zhang, C. Lv, K. Li, L. Pan, Inorg. Chim. Acta 2018, 469, 44-50;

DOI:10.1016/j.ica.2017.09.011

(e) D. Sadhukhan, M. Maiti, E. Zangrando, S. Pathan, S. Mitra, A. Patel, Polyhedron 2014, 69, 1-9;

DOI:10.1016/j.poly.2013.11.007

(f) Y. Tan, Acta Chim. Slov. 2019, 66, 1002-1009.

DOI:10.17344/acsi.2019.5297

3. (a) B. Shaabani, A. A. Khandar, H. Mobaiyen, N. Ramazani, S. S. Balula, L. Cunha-Silva, Polyhedron 2014, 80, 166-172; DOI:10.1016/j.poly.2014.03.033

(b) E. M. M. Ramadan, I. M. El-Mehasseb, Transition Met. Chem. 1998, 23, 183-189; DOI:10.1023/A:1006959513023

(c) M. Bagherzadeh, M. Amini, H. Parastar, M. Jalali-Heravi, A. Ellern, L. K. Woo, Inorg. Chem. Commun. 2012, 20, 86-89; DOI:10.1016/j.inoche.2012.02.023 (d) Z. Ma, M. Sutradhar, A. V. Gurbanov, A. M. Maharramov, R. A. Aliyeva, F. S. Aliyeva, F. N. Bahmanova, V. I. Mardanova, F. M. Chyragov, Polyhedron 2015, 101, 14-22;

DOI:10.1016/j.poly.2015.07.054

(e) S. Yousef Ebrahimipour, M. Abaszadeh, J. Castro, M. Seifi, Polyhedron 2014, 79, 138-150.

DOI:10.1016/j.poly.2014.04.069

4. (a) O. Pouralimardan, A. C. Chamayou, C. Janiak, H. Hosseini-Monfared, Inorg. Chim. Acta, 2007, 360, 1599-1608; DOI:10.1016/j.ica.2006.08.056

(b) R. Bikas, M. Ghorbanloo, R. Sasani, I. Pantenburg, G. Meyer, J. Coord. Chem., 2017, 70, 819-830;

DOI:10.1080/00958972.2017.1281918

(c) M. S. Shongwe, K. S. Al-Barhi, M. Mikuriya, H. Adams, M. J. Morris, Chem. Eur. J. 2014, 20, 9693-9701.

DOI:10.1002/chem.201402634

5. G. M. Sheldrick, Acta Crystallogr. 2015, C71, 3-8.

6. O. Pouralimardan, A.-C. Chamayou, C. Janiak, H. Hosseini-Monfared, Inorg. Chim. Acta 2007, 360, 1599-1608.

DOI:10.1016/j.ica.2006.08.056

7. W. J. Geary, Coord. Chem. Rev. 1971, 7, 81-122.

DOI:10.1016/S0010-8545(00)80009-0

8. (a) C. Bourchameni, C. Beghidja, A. Beghidja, P. Rabu, R. Welter, Polyhedron 2011, 30, 1774-1778;

DOI:10.1016/j.poly.2011.04.007

(b) B. F. Ali, Z. Judeh, K. Ayub, Polyhedron 2015, 101, 118125. DOI:10.1016/j.poly.2015.07.036

9. N. Zhang, C.-Y. Huang, D.-H. Shi, Z.-L. You, Inorg. Chem. Commun. 2011, 14, 1636-1639. DOI:10.1016/j.inoche.2011.06.027

10. S. Chandra, A. K. Sharma, J. Coord. Chem. 2009, 62, 36883700. DOI:10.1080/00958970903121305

11. S. Chandra, A. K. Sharma, Spectrochim. Acta A 2009, 72, 851857. DOI:10.1016/j.saa.2008.12.022

12. Y.-M. Zhou, X.-R. Ye, F.-B. Xin, X.-Q. Xin, Transition Met. Chem. 1999, 24, 118-120. DOI:10.1023/A:1006989707001

13. (a) A. Gold, K. Jayaraj, P. Doppelt, R. Weiss, G. Chottard, E. Bill, X. Ding, A. X. Trautwein, J. Am. Chem. Soc. 1988, 110, 5756-5761; DOI:10.1021/ja00225a028

(b) M. J. Gunter, P. Turner, J. Mol. Catal. A 1991, 66, 121-127. DOI:10.1016/0304-5102(91)85027-Y

14. K. Srinivas, P. Michand, J. K. Kochi, J. Am. Chem. Soc. 1986, 108, 2309-2320. DOI:10.1021/ja00269a029

15. Y. Lei, Q. W. Yang, Inorg. Nano-Met. Chem. 2017, 47, 446-449. DOI:10.1080/15533174.2016.1186070

\section{Povzetek}

Sintetizirali smo nov enojedrni manganov(II) bromido kompleks $\left[\mathrm{MnL}^{1} \mathrm{Br}_{2}\left(\mathrm{OH}_{2}\right)\right]$ (1), in nov enojedrni manganov(II) nitrato kompleks $\left[\mathrm{Mn}\left(\mathrm{L}^{2}\right)_{2}\left(\mathrm{ONO}_{2}\right)\left(\mathrm{OH}_{2}\right)\right] \mathrm{NO}_{3}(2)$ z hidrazonskim ligandom 4-hidroksi- $N^{\prime}$-(piridin-2-ilmetilen)benzohidrazidom $\left(\mathrm{HL}^{1}\right)$ in $N^{\prime}$-(piridin-2-ilmetilen)izonikotinohidrazidom $\left(\mathrm{HL}^{2}\right)$ ter ju okarakterizirali s fiziko-kemijskimi metodami in rentgensko monokristalno difrakcijo. Strukturna analiza razkriva, da ima Mn atom v kompleksu 1 oktaedrično koordinacijo, v kompleksu 2 pa pentagonalno bipiramidalno koordinacijo. Določili smo katalitične lastnosti obeh kompleksov za epoksidacijo stirena.

Except when otherwise noted, articles in this journal are published under the terms and conditions of the Creative Commons Attribution 4.0 International License 